\title{
PERANCANGAN SISTEM RESERVASI DAN PROMOSI HOTEL BERBASIS WEBSITE
}

\author{
Vivi Sahfitri \\ Fakultas Ilmu Komputer, Universitas Bina Darma \\ Jalan Jenderal Ahmad Yani No. 3 Palembang 30624 \\ Telp.0711-515679, Fax.0711-515582 \\ e-mail : vivi_sahfitri@binadarma.ac.id
}

\begin{abstract}
The rapid development of information technology, triggering every area of life must be able to innovate so as not to lag or even disappear. One of the areas that has been utilizing many technologies is the economic and business areas. One of the businesses that is currently growing is the hospitality business. Regional potential in Indonesia that provides many benefits for tourists ranging from sport or recreation to make the business of hospitality become a promising effort. The number of hotels established, making business competition increasingly higher. facilities, promotion, service and convenience in obtaining information and transaction into a factor that can impact the business progress of the hotel. Fast information service especially for reservation is indispensable. This research aims to design a reservation and promotion system in a Web-based hospitality business. The methods used in this research are the Software Development Life Cycle (SDLC) method as well as system design using Unified Modelling Language (UML). This research generates a prototype reservation system and promotion of a website-based hospitality business that can be implemented to build information systems and can then be used to facilitate the dissemination of information/hotel promotion and facilitate consumers to make reservations online.
\end{abstract}

Keywords : System design, reservation, promotion, hospitality business, Unified Modeling Language (UML), Software Development Life Cycle (SDLC)

\begin{abstract}
ABSTRAK
Perkembangan teknologi informasi yang semakin pesat, memicu setiap bidang kehidupan harus mampu berinovasi agar tidak tertinggal atau bahkan hilang begitu saja. salah satu bidang yang telah banyak memanfaatkan teknologi adalah bidang ekonomi dan bisnis. Salah satu bisnis yang saat ini terus berkembang adalah bisnis perhotelan. Potensi daerah di indonesia yang memberikan banyak manfaat bagi wisatawan mulai dari olahraga ataupun rekreasi menjadikan bisnis perhotelan menjadi usaha yang menjanjikan. Semakin banyaknya hotel yang didirikan, membuat persaingan bisnis dibidang ini semakin tinggi. fasilitas, promosi, pelayanan serta kemudahan dalam memperoleh informasi dan bertransaksi menjadi faktor yang dapat memberikan dampak bagi kemajuan bisnis hotel tersebut. Layanan informasi yang cepat terutama untuk reservasi sangat diperlukan. Penelitian ini bertujuan untuk merancang sistem reservasi dan promosi pada usaha perhotelan yang berbasis web. Metode yang digunakan dalam penelitian ini adalah metode Software Development Life Cycle (SDLC) serta perancangan sistem menggunakan Unified Modelling Language (UML). Penelitian ini menghasilkan sebuah prototype sistem
\end{abstract}


reservasi dan promosi usaha perhotelan berbasis website yang dapat diimplementasikan untuk membangun sistem informasi dan nantinya dapat digunakan untuk memudahkan dalam penyebaran informasi /promosi hotel serta memudahkan konsumen untuk melakukan reservasi secara online.

Kata Kunci : Perancangan Sistem, Reservasi, Promosi, Usaha Perhotelan, Unified Modelling Language(UML), Software Development Life Cycle (SDLC)

\section{PENDAHULUAN}

Indonesia merupakan negara yang memiliki ribuan pulau yang memiliki keindahan dan keunikan tersendiri. Banyaknya pulau dengan berbagai keindahan yang diberikan, menjadikan pulau-pulau di Indonesia banyak menjadi destinasi wisata bagi turis baik domestik maupun mancanegara. Keanekaragaman budaya, adat istiadat, sejarah, kerajinan daerah dan potensi lain dari daerah-daerah di Indonesia menjadikan sektor kepariwisataan di Indonesia berkembang cukup pesat [1].

Berdasarkan data dari Badan Pusat Statistik, dalam lima tahun terakhir (20142018) kedatangan (kunjungan) turis mancanegara ke Indonesia memiliki rataratapertumbuhan mencapai $14 \%$ pertahun. Angka ini meningkat jika dibandingkan dengan rata-rata pertumbuhan kunjungan turis mancanegara pada 5 tahun sebelumnya (2009-2013) dengan rata-rata pertumbuhan 9\% per tahun. Gambar 1 memberikan gambaran peningkatan ratarata pertumbuhan kunjungan turis mancanegara ke Indonesia [2].

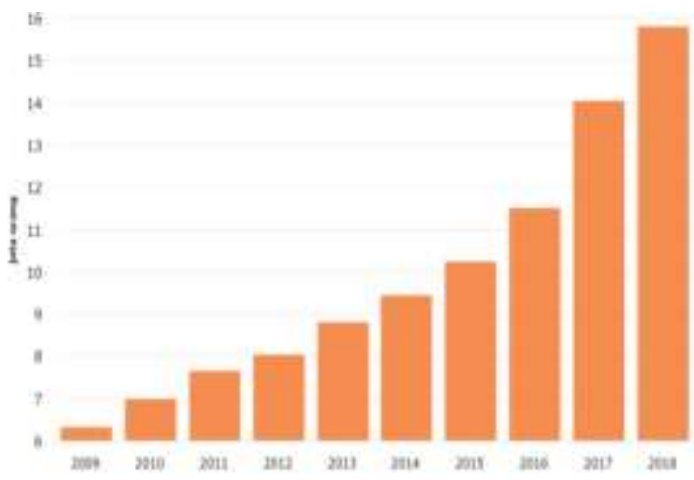

Gambar 1. Pertumbuhan Kunjungan Turis Mancanegara di Indonesia Meningkatnya kunjungan wisatawan baik domestik maupun mancanegara memberikan dampak pada usaha lain salah satunya adalah usaha dibidang perhotelan. Para wisatawan yang datang, pasti membutuhkan tempat untuk tinggal atau bermalam. Hal ini berdampak semakin menjamurnya keberadaan hotel di daerah-daerah yang menjadi tujuan wisata para wisatawan. Para pemilik modal berlomba untuk mendirikan tempat menginap bagi para wisatawan dengan berbagai penawaran yang menarik serta kemudahan dalam melakukan pemesanan atau reservasi. Salah satu faktor yang dapat memberikan kemudahan bagi para wisatawan untuk memperoleh informasi maupun melakukan 
reservasi adalah penggunaan teknologi informasi. Gambar 2 menunjukkan tingkat hunian hotel di Indonesia yang semakin meningkat dalam satu tahun terakhir [3].

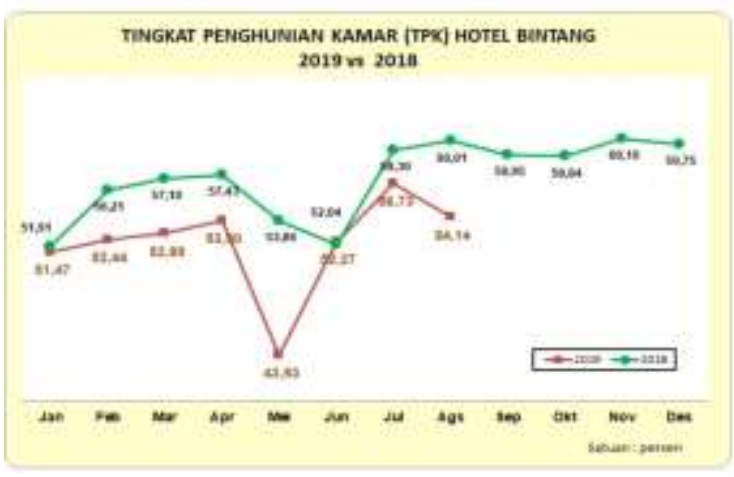

Gambar 2. Tingkat Hunian Hotel di Indonesia

Teknologi Informasi merupakan faktor penting yang dapat mendorong kemajuan usaha salah satunya pada bidang jasa perhotelan. Adopsi teknologi infomasi pada bidang usaha perhotelan memberikan dampak positif bagi usaha. Dengan memanfaatkan teknologi informasi dapat meberikan kemudahan bagi operasional hotel yang juga dapat meningkatkan kualitas pelayanan, efisiensi dan biaya operasional. Karena dengan memanfaatkan teknologi informasi dapat mengatasi masalah-masalah yang sering dihadapi pengusaha perhotelan seperti, mobilitas staff yang tinggi, kualitas teknik yang tidak stabil, kualitas fungsional yang volatile, ketepatan waktu dan ketepatan pelayanan [4]. Penggunaan teknologi Informasi, terutama teknologi komputer memberikan berbagai kemudahan, kecepatan dan ketepatan dalam mendapatkan dan mengelola berbagai macam data dan informasi. Salah teknologi komputer yang paling banyak dimanfaatkan adalah teknologi Internet [5]. Internet adalah jaringan komputer global yang menghubungkan satu komputer dengan komputer lainnya [6]. Dengan adanya jarngan komputer, pengguna dapat saling berinteraksi melalui halaman website. Website dapat dengan mudah digunakan oleh seluruh perangkat elektronik yang terkoneksi dengan internet dan memiliki browser [7].

Hotel anugerah adalah salah satu hotel bintang dua yang ada di kota Palembang. Hotel ini memiliki beberap tipe kamar dengan harga dan fasilitas yang berbeda, ruang pertemuan, laundry dan coffe shop. Selama ini transaksi yang dilakukan di hotel ini masih menggunakan cara-cara manual. Sebagai contoh, untuk mendapatkan informasi tentang tipe kamar, fasililtas dan tarif kamar customer harus datang langsung atau melakukan panggilan telepon untuk mencapatkan informasi tersebut. Selain itu untuk melakukan reservasi, customer juga hanya dapat melakukan melalui telepon langsung ke pihak hotel atau langsung datang ke hotel tersebut. Penyebaran informasi dan transaksi yang belum memanfaatkan teknologi informasi dan komunikasi menjadi kendala bagi pihak hotel untuk 
meningkatkan jumlah pengunjung yang menginap. Keluasan informasi yang diberikan serta kemudahan dalam mengaksesnya merupakan salah satu bentuk usaha untuk dapat bersaing dalam industri perhotelan agar terus dapat bertahan dibidang usaha tersebut. Dalam industri perhotelan, terdapat beberapa sistem informasi yang dapat bangun atau dikembangkan. Pada umumnya terdapat empat katagori sistem yang ada pada industri perhotelan, yaitu Sistem yang menangani back office, front Office, Sistem Manajemen Restaurant dan sistem yang terkait dengan tamu hotel. Gambar 3 menunjukkan Sistem berbasis IT yang mungkin dikembangkan dalam industri Perhotelan [8].
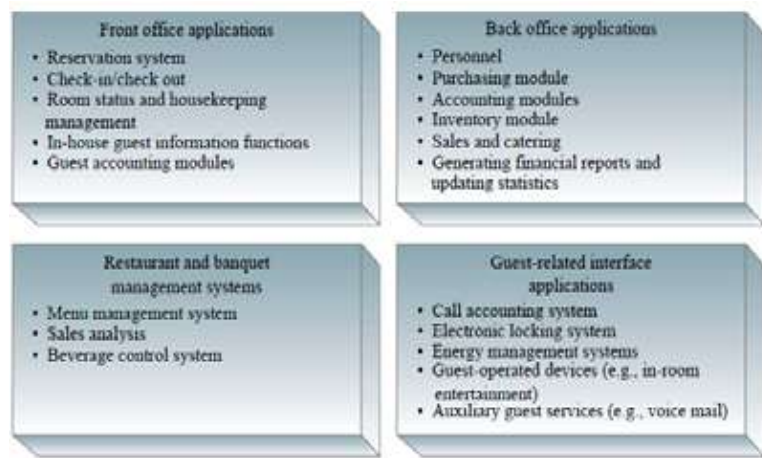

Gambar 3. Sistem berbasis IT pada Industri

Perhotelan

Reservasi adalah suatu sistem yang ada pada sebuah hotel. Reservasi hotel dapat dilakukan secara langsung dengan menghubungi hotel melalui media Telepon. Sistem Reservasi sendiri merupakan pusat darinoperasi bagai front
Office, dimana sistem menangani registrasi tamu, Proses check in, dan Check Out, melakukan pengarsipan, konfirmasi pembayaran serta permintaan atau pemesanan kamar hotel [9]. Untuk mempermudah proses reservasi untuk kamar hotel sekaligus dapat menjadi sarana untuk melakukan promosi secara lebih luas, perancangan suatu sistem reservasi hotel yang menarik dan dapat diimplementasikan menjadi sebuah sistem informasi berbasis IT perlu dilakukan. Hal ini juga sebagai alternatif untuk dapat bersaing dengan usaha sejenis yang semakin menjamur di berbagai wilayah di seluruh Indonesia. Penelitian ini bertujuan untuk menganalisis kebutuhan sistem informasi pada hotel yang menjadi objek serta membuat perancangan sistem reservasi dan promosi berbasis website yang nantinya dapat menjadi dasar untuk membangun sistem informasi reservasi dan promosi bagi hotel tersebut.

\section{METODE PENELITIAN}

Metode penelitian berkaitan dengan prosedur atau langkah-langkah atau tahapan yaang dilakukan dalam melaksanakan kegiatan penelitian. Dengan adanya prosedur atau tahapan yang jelas, maka penelitian akan terlaksana secara logis dan sistematis. 


\subsection{Metode Perancangan Sistem}

Merancang dan membangun perangkat lunak yang berbeda, akan membutuhkan proses yang berbeda pula.

Dalam Software Engineering tidak ada metode atau teknik yang dapat diterapkan untuk beberapa Perangkat Lunak yang berbeda [10]. Meskipun begitu, dalam membangun perangkat lunak secara umum harus melalui empat aktivitas dasar yang berkaitan dengan rekayasa Perangkat lunak [11], yaitu; Spesifikasi software, Desain dan Implementasi software, Validasi Software, serta Evolusi software. Dalam membuat rancangan sistem reservasi dan promosi hotel berbasis webste ini, digunakan tahapan yang terdapat dalam metode Software Development Life Cycle (SDLC). SDLC merupakan suatu pendekatan yang dilakukan secara bertahap untuk menganalisa dan membangun sebuah rancangan sistem menggunakan siklus yang lebih spesifik terhadap kebutuhan pengguna [12]. Terdapat empat fase dalam SDLC [13], yaitu Fase Perencanaan, Fase Analisis, Fase Perancangan dan Fase Implementasi.yang dapat terlihat pada gambar 3.

Pada penelitian ini fase yang dilakukan hanya sampai fase desain, yang menampilkan rancangan arsitektur Perangkat Lunak, rancangan antar muka,
Rancangan Basis data yang dilengkapi dengan spesifikasi file yang dibutuhkan. Pada penelitian selanjutnya dapat dilakukan tahapan implementasi, yaitu fase Coding yang mengimplementasikan rancangan kedalam bahasa pemrograman tertentu sehingga dapat menjadi sistem atau Perangkat Lunak yang siap diuji dan selanjutnya diimplementasikan oleh pengguna.

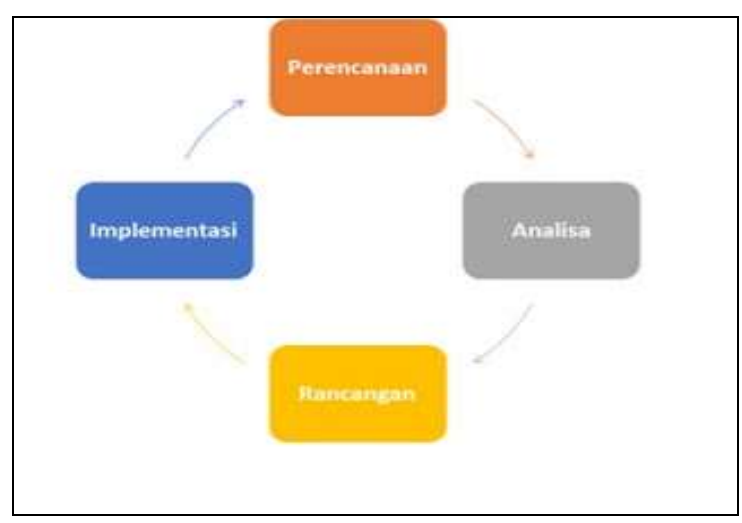

Gambar 4. Fase Sdlc

\subsection{Analisis Sistem}

Sebelum membuat rancangan sistem reservasi dan promosi hotel berbasis website, terlebih dahulu dilakukan analisis terhadap kebutuhan data yang berkaitan dengan kegiatan perancangan sistem agar rancangan yang dihasilkan dapat sesuai dengan kondisi yang ada sehingga pada saat akan diimplementasikan dalam suatu sistem informasi, hasilnya akan sesuai dengan yang diharapkan. Dalam analisis sistem hal-hal yang menjadi dasar adalah mengapa perlu dilakukan perancangan sistem untuk membangun sistem reservasi 
dan promosi berbasis web tersebut. Selain itu dalam tahap ini ditentukan pula analisis kebutuhan informasi dari sistem yang akan dirancang dan dibangun tersebut. Analisis kebutuhan sistem ini dibagi menjadi dua yaitu analisis kebutuhan data fungsional dan analisis kebutuhan data non fungsional. Analisis kebutuhan fungsional adalah jenis kebutuhan yang berkaitan dengan prosesproses yang akan dilakukan oleh sistem dan informasi-informasi yang akan dihasilkan oleh sistem. Sedangkan kebutuhan non fungsional adalah tipe kebutuhan yang berkaitan dengan peralatan dan prilaku yang dimililiki oleh sistem.

\subsection{Penelitian Terdahulu.}

Penelitian terdahulu sangat penting untuk diketahui utnuk memperoleh informasi yang lebih banyak terutama yang berkaitan dengan perancangan sistem untuk bidang perhotelan, agar hasil rancangan yang didapat lebih baik dan sesuai dengan tujuan yang ingin dicapai. Penelitian yang berkaitan dengan sistem informasi berbasis website sudah banyak dilakukan. Berikut ini beberapa penelitian yang berkaitan dengan Sistem informasi berbasis website.

Penelitian dengan judul Rancang Bangun Sistem Informasi Reservasi hotel berbasis Web dengan Framework Codeigniter yang dilakukan oleh Friska Dian Lolo Tandilian, I made Adi Purwantara dan Naser jawas. Penelitian ini menghasilkan sebuah sistem Informasi Reservasi Hotel Berbasis Web dengan menerapkan Framework Codeigniter [14]. Penelitian lain dilakukan oleh Nuraini Purwandari dan Arie Kusumawati dalam artikel jurnal yang berjudul Aplikasi Simpan Pinjan Pada Koperasi Karyawan Kalbis Sejahtera Berbasis Website. Penelitian menghasilkan sebuah aplikasi simpan pinjam berbasis website yang dapat melakukan penginputan data simpan pinjam anggota, membuat laporan simpan pinjam secara up to date dan dapat diakses secara real time oleh anggota kapan saja [15]. Penelitian lain yang berjudul Perancangan Website Sebagai Media Promosi dan Penjualan Produk yang dilakukan oleh Victor Marudut Mulia Siregar menghasilkan rancangan website yang dapat diimplementasikan menjadi sebuah Website yang dapat digunakan unruk melakukan promosi dan penjualan produk [16]. Penelitian yang dilakukan oleh Shanti Kusuma Dewi dan Annisa Kesy Garside dengan judul Perancangan Website Sebagai Media Promosi dan Penjualan pada Home Industri Abon menghasilkan sebuah website sebagai sistem Penjualan Online dengan Tool 
Content Management System (CMS) Opencart yang bertujuan kegiatan pemasaran akan lebih efektif dan biasa meningkatkan omset Penjualan [17].

\section{HASIL DAN PEMBAHASAN}

Penelitian ini menghasilkan rancangan sistem reservasi dan Promosi hotel berbasis website. Tahapan pentng yang dilakukan dalam membuat rancangan adalah proses yang dilakukan. Proses yang dilakukan harus disesuaikan dengan kebutuhan sistem serta kemampuan dari pengguna sistem tersebut, Sehingga sistem yang akan dibangun nantinya dapat berjalan dengan baik sesuai dnegan fitur dan fungsi yang sesuai dengan harapan pengguna [18].

\section{a. Perancangan Sistem}

Tahap Perancangan sistem dilakukan dengan tujuan untuk mengetahui gambaran proses yang terjadi dalam sistem yang akan dibangun. Tahap ini perlu dilakukan dan merupakan bagian terpenting dalam proses pembangunan suatu Perangkat lunak karena dalam tahap ini dilakukan untuk memberikan spesifikasi, merancang, membuat model serta mendokumentasikan aspek-aspek dari Perangkat lunak (Software) yang akan dibangun dengan menggunakan Diagram Unified Modelling Language (UML). a) Use Case Diagram

Use Case menggambarkan atau mendeskripsikan hubungan dan interaksi antara aktor yang terlibat dalam sistem yang akan dibangun.

Berdasarkan gambar 4, dalam sistem yang akan dibangun aktor yang akan terlibat adalah Administrator yang menjadi pengelola sistem, Guest/Customer yang dapat melakukan kunjungan ke website untuk mendapatkan informasi terkait dengan jasa perhotelan yang mereka butuhkan, Member merupakan pelanggan tetap dari hotel yang sudah memiliki akun dan data yang telah terdaftar pada sistem database hotel. Sebagai aktor terakhir adalah pimpinan yang dapat mengakses laporan-laporan yang berkaitan dengan transaksi yang terjadi.

\section{b) Class Diagram}

Diagram ini berfungsi untuk mengidentifikasikan content (isi) Informasi yang ada pada Perangkat Lunak (Sistem) yang akan dibangun. Class Diagram pada gambar 5 menunjukan atribut dan operasi yang dapat dilakukan pada sistem nantinya. Simbol panah pada diagram berfungsi untuk menyambung atribut satu dengan yang lainnya. 


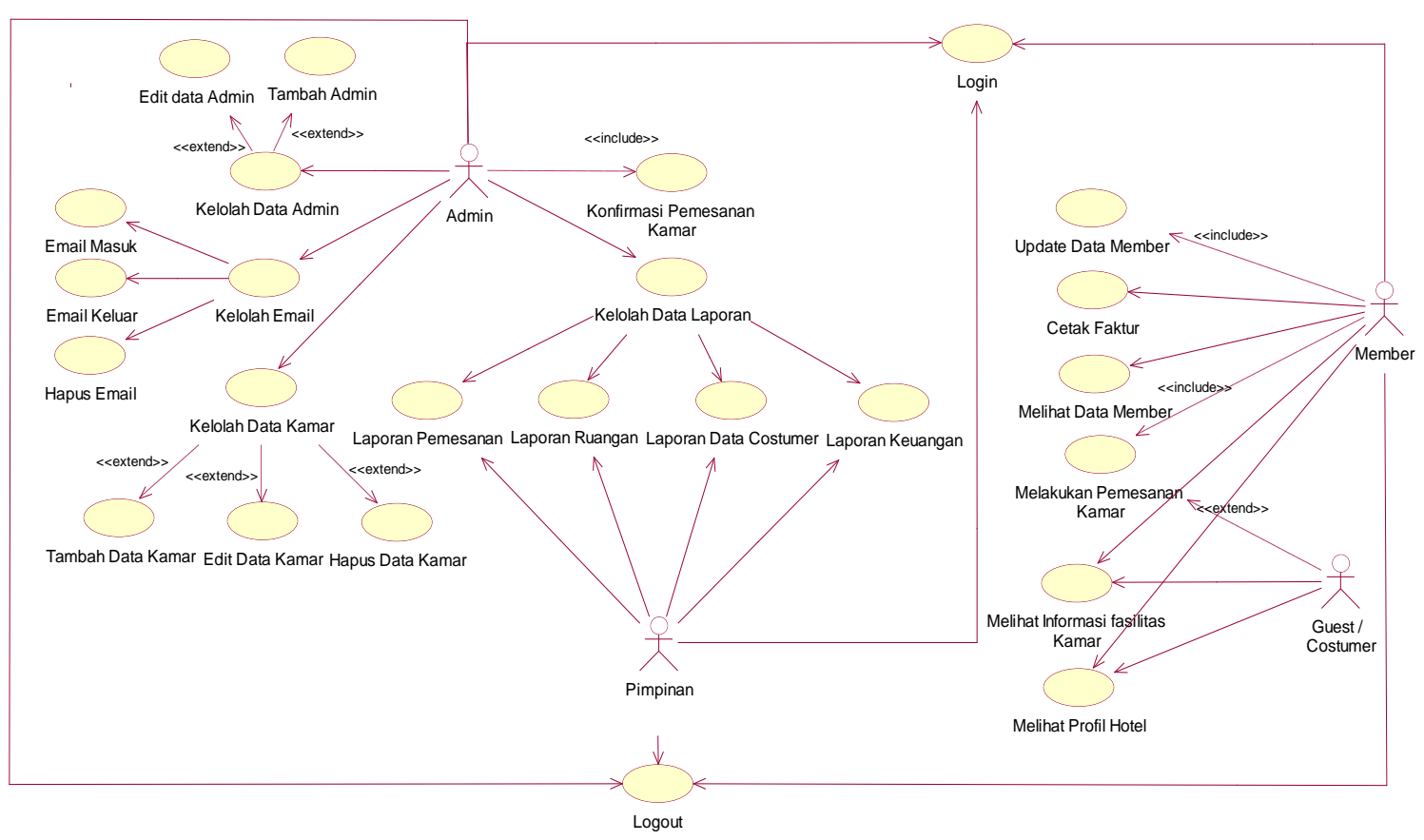

Gambar 4. Use Case Sistem Reservasi dan Promosi

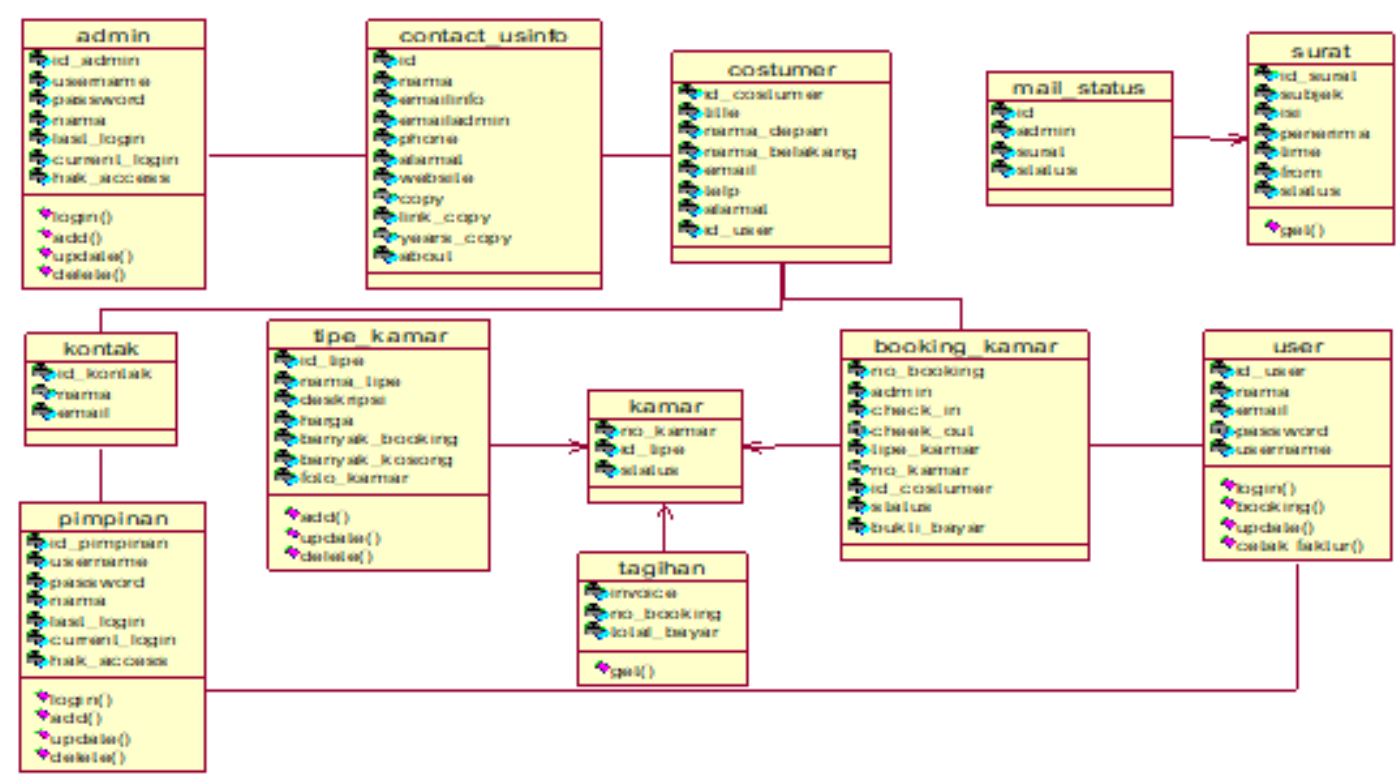

Gambar 5. Class Diagram Reservasi dan Promosi

\section{c) Activity Diagram}

Activity Diagram menggambarkan semua aktivitas yang dimiliki oleh admin dan system. Dalam perancangan ini terdapat 4 activity diagram yaitu diagram aktivitas untuk admin, Diagram aktivitas untuk member, Diagram aktivitas customer/guest dan Diagram aktivitas untuk pimpinan. Gambar 6, gambar 7, gambar 8 dan gambar 9 menunjukan activity diagram sistem. 


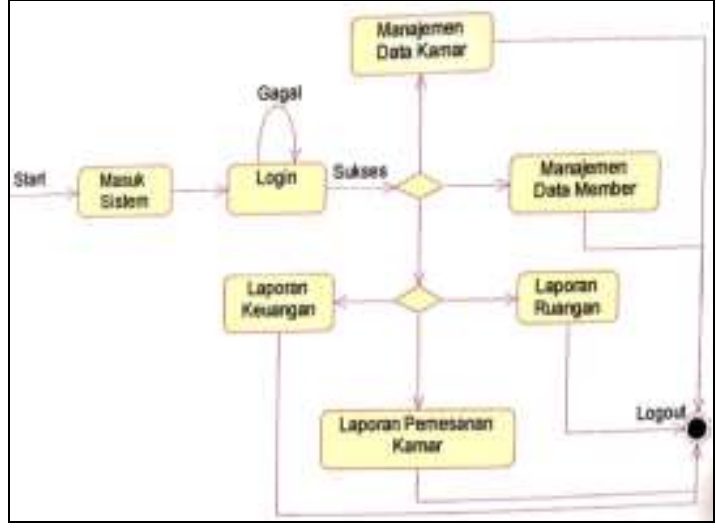

Gambar 6. Activity Diagram Admin

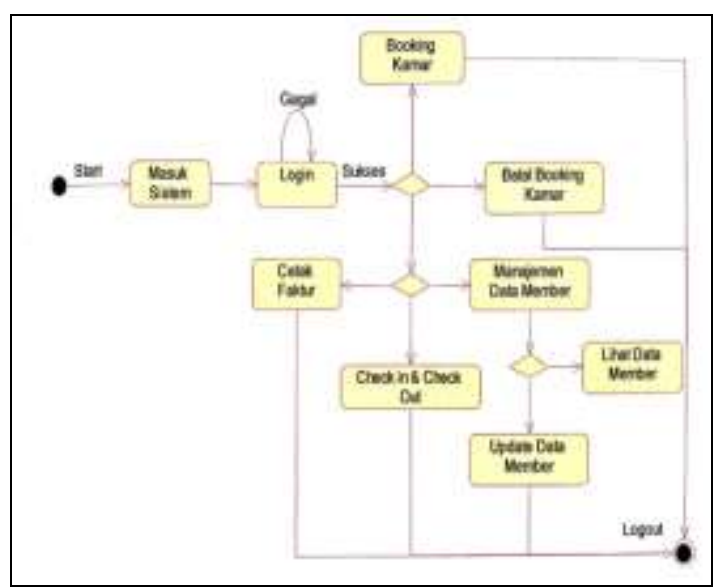

Gambar 7. Activity Diagram Member

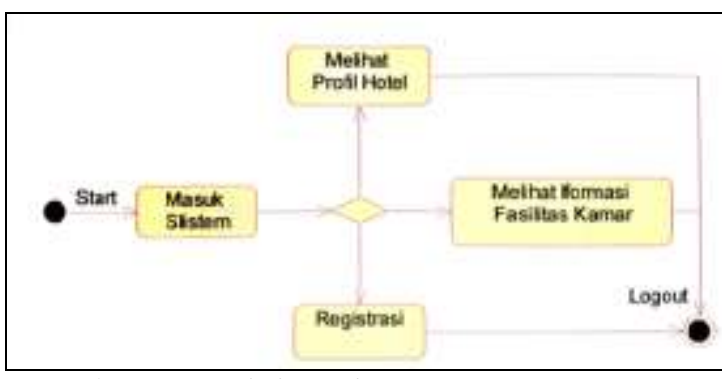

Gambar 8. Activity Diagram Guest/customer

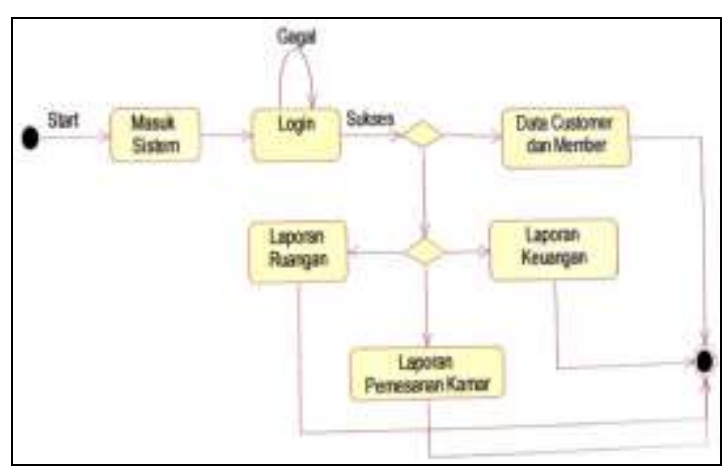

Gambar 9. Activity Diagram Pimpinan

\section{b. Perancangan Basis Data}

Perancangan Basis Data bertujuan untuk memberikan spesifikasi file yang akan memberikan rincian yang lengkap dengan rancangan tabel-tabel yang dibentuk. Tabel 1, tabel 2, tabel 3,tabel 4 dan tabel 5 menunjukkan basis data yang dirancang untuk membangun sistem nantinya.

Tabel 1. Rancangan Basis Data Untuk Admin

\begin{tabular}{|l|c|c|l|}
\hline Nama Field & Jenis & Ukuran & \multicolumn{1}{|c|}{ Keterangan } \\
\hline id_admin & Int & 10 & id_admin \\
\hline $\begin{array}{l}\text { Username } \\
\text { (Primary } \\
\text { Key) }\end{array}$ & Varchar & 50 & Nama user nya \\
\hline Password & Varchar & 50 & Kata sandi \\
\hline nama & Varchar & 30 & Nama pengguna \\
\hline last_login & Varchar & 20 & Terakhir akses \\
\hline current_login & Varchar & 20 & Saat mengakses \\
\hline hak_access & Varchar & 2 & Hak keseluruhan \\
\hline
\end{tabular}

Tabel 2. Rancangan Basis Data Untuk

\begin{tabular}{|l|c|c|l|}
\multicolumn{5}{c}{ User } \\
\hline Nama Field & Jenis & Ukuran & Keterangan \\
\hline $\begin{array}{l}\text { id_user } \\
\text { (Primary } \\
\text { Key })\end{array}$ & Varchar & 12 & id_User \\
\hline nama & Varchar & 50 & Nama lengkap \\
\hline username & Varchar & 25 & $\begin{array}{l}\text { Nama } \\
\text { pengguna }\end{array}$ \\
\hline email & Varchar & 15 & Email aktif \\
\hline password & Varchar & 15 & $\begin{array}{l}\text { Password } \\
\text { untuk login }\end{array}$ \\
\hline
\end{tabular}

Tabel 3. Rancangan Basis Data Untuk

\begin{tabular}{|l|l|c|l|}
\multicolumn{1}{|c}{ Booking } \\
\hline \multicolumn{1}{|c|}{ Nama Field } & Jenis & Ukuran & Keterangan \\
\hline $\begin{array}{l}\text { no_booking } \\
\text { (Primary Key })\end{array}$ & Int & 12 & no_booking \\
\hline admin & Varchar & 50 & Petugas admin \\
\hline check_in & Varchar & 15 & Tamu masuk \\
\hline check_out & Varchar & 15 & Tamu keluar \\
\hline tipe_kamar & Int & 11 & Jenis kamar \\
\hline no_kamar & Int & 11 & Nomor kamar \\
\hline id_costumer & Int & 11 & Nomor tamu \\
\hline status & Varchar & 30 & keterangan \\
\hline
\end{tabular}


Tabel 4. Rancangan Basis Data Untuk

\section{Customer}

\begin{tabular}{|l|c|c|l|}
\hline \multicolumn{1}{|c|}{ Nama Field } & Jenis & Ukuran & Keterangan \\
\hline $\begin{array}{l}\text { id_costumer } \\
\text { (Primary Key) }\end{array}$ & Int & 11 & id_costumer \\
\hline id_user & Int & 10 & $\begin{array}{l}\text { Id user } \\
\text { ( pengguna })\end{array}$ \\
\hline title & Varchar & 10 & $\begin{array}{l}\text { Sebutan Mr / } \\
\text { Mrs }\end{array}$ \\
\hline nama_depan & Varchar & 30 & Nama depan \\
\hline nama_belakang & Varchar & 30 & $\begin{array}{l}\text { Nama } \\
\text { kepanjangan }\end{array}$ \\
\hline email & Varchar & 30 & $\begin{array}{l}\text { Alamat } \\
\text { email }\end{array}$ \\
\hline telp & Varchar & 20 & $\begin{array}{l}\text { Nomor } \\
\text { handphone }\end{array}$ \\
\hline alamat & Text & & Alamat \\
\hline
\end{tabular}

Tabel 5. Rancangan Basis Data Untuk Pimpinan

\begin{tabular}{|l|c|c|l|}
\hline \multicolumn{1}{|c|}{ Nama Field } & Jenis & Ukuran & Keterangan \\
\hline $\begin{array}{l}\text { id_pimpinan } \\
\text { (Primary Key) }\end{array}$ & Int & 10 & id_pimpinan \\
\hline username & Varchar & 50 & $\begin{array}{l}\text { Nama user } \\
\text { nya }\end{array}$ \\
\hline password & Varchar & 50 & Kata sandi \\
\hline nama & Varchar & 30 & $\begin{array}{l}\text { Nama } \\
\text { pengguna }\end{array}$ \\
\hline last_login & Varchar & 20 & $\begin{array}{l}\text { Terakhir akses } \\
\text { website }\end{array}$ \\
\hline current_login & Varchar & 20 & $\begin{array}{l}\text { Saat } \\
\text { mengakses } \\
\text { website }\end{array}$ \\
\hline hak_access & Varchar & 2 & $\begin{array}{l}\text { Hak } \\
\text { keseluruhan } \\
\text { mengakses } \\
\text { web }\end{array}$ \\
\hline
\end{tabular}

\section{c. Website Interface}

Website interface berfungsi sebagai penghubung antara pengguna (user) dalam hal ini adalah administrator, User, Customer dan Pimpinan dengan Website. Gambar 10 menampilkan halaman login untuk Administrator sebagai Pengelola sistem untuk masuk keaplikasi. Gambar 11 menunjukkan tampilan menu yang terdapat dalam login administrator. Admin dapat mengelola sistem secara keseluruhan sekaligus merawat sistem yang berkaitan dengan informasi yang ada didalan sistem. Selain administrator, aktor lain yang bisa melakukan login adalah pimpinan.

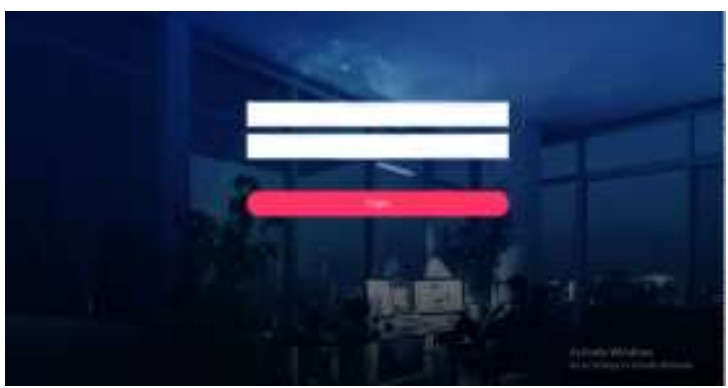

Gambar 10. Tampilan Login Administrator

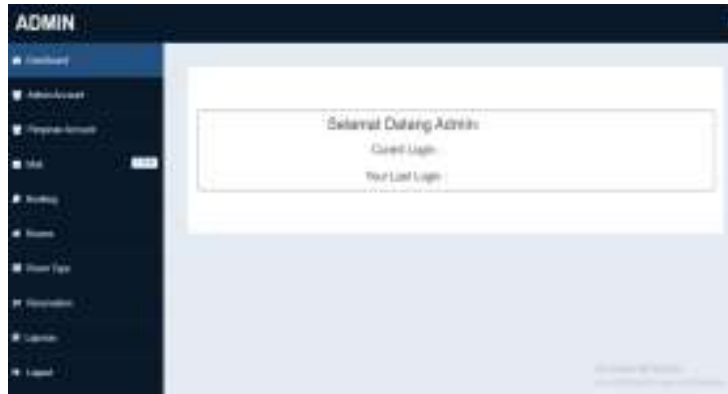

Gambar 11. Tampilan Menu Administrator

Setelah melakukan login, seorang pimpinan dapat melihat laporan yang berkaitan dengan informasi yang tersedia dalam sistem. Gambar 12 menunjukan tampilan login Pimpinan dan gambar 13 menunjukkan menu yang ada dalam login pimpinan

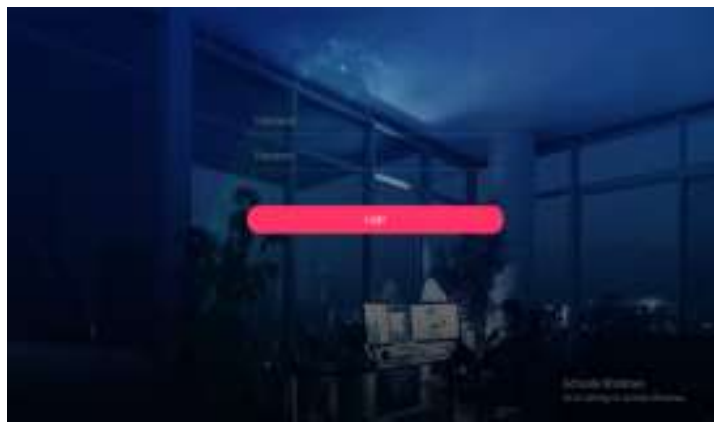

Gambar 12 . Tampilan Login Pimpinan 


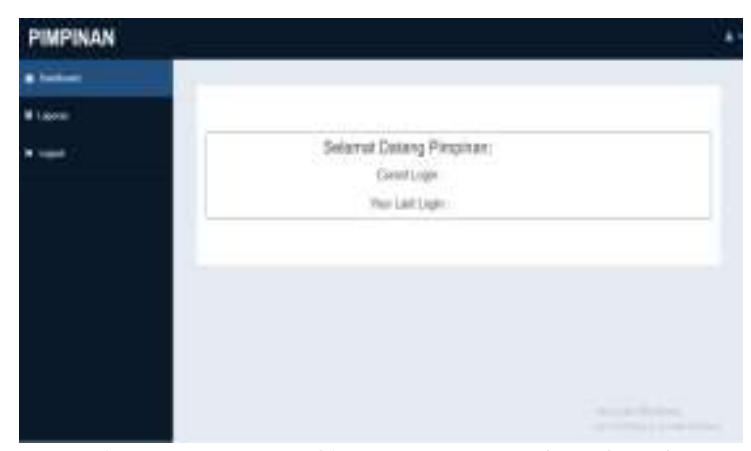

Gambar 13 . Tampilan Menu Login Pimpinan

Selain menu administrator dan pimpinan, website juga memberikan halaman bagi pengunjung yang menampilkan menu yang dapat dilihat oleh user. Gambar 14 menampilkan halaman utama dari prototype sistem reservasi dan promosi.

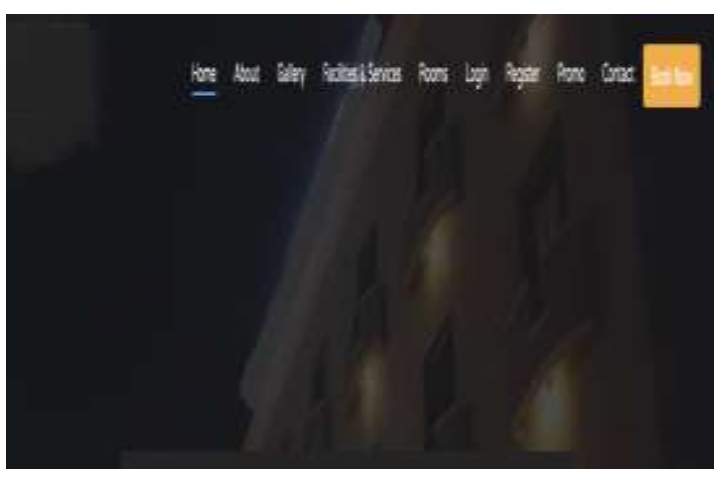

Gambar 14. Tampilan Halaman Utama

\section{Website}

Halaman utama juga menampilkan beberapa menu yang dibutuhkan oleh pengunjung untuk mengetahui lebih banyak tentang segala hal yang berkaitan dengan hotel tersebut yaitu; menampilkan Fasilitas dan pelayanan yang dimiliki hotel, kamar, serta promo yang dapat diperoleh oleh pengunjung.

Untuk dapat melakukan pemesanan atau booking room, Pengunjung harus melakukan registrasi terlebih dahulu seperti terlihat pada gambar 15 , agar dapat melakukan login untuk melakukan reservasi yang dibutuhkan seperti terlihat pada gambar 16. Sedangkan gambar 17 dan gambar 18 menunjukkan laporan yang dapat dihasilkan oleh sistem ini.

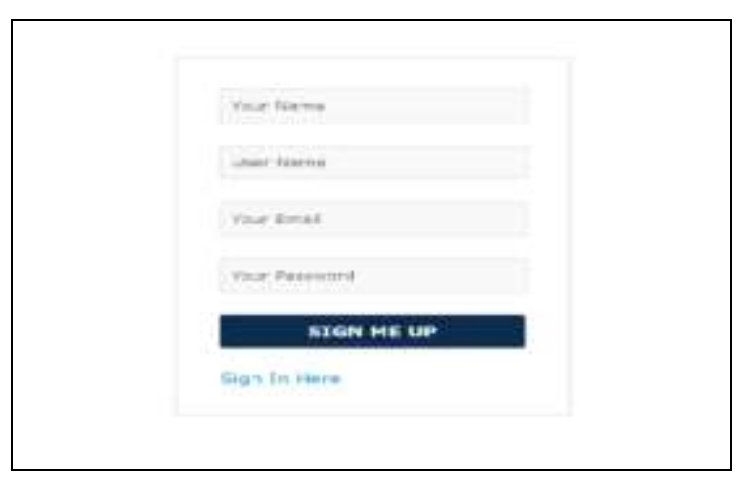

Gambar 15 . Halaman Registrasi User

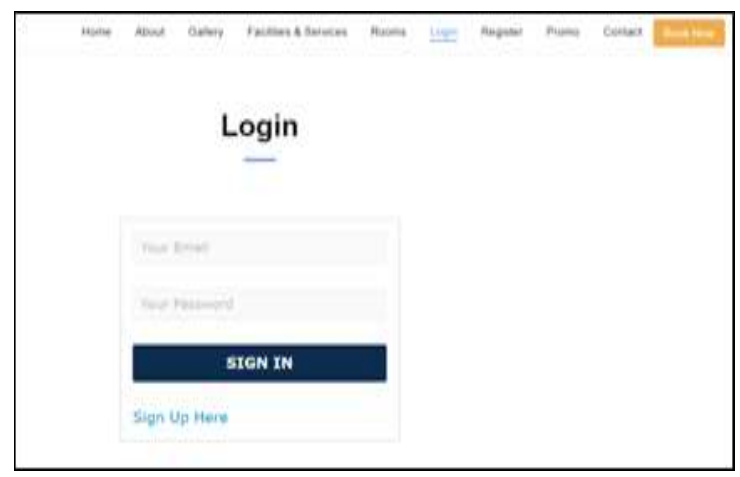

Gambar 16 . Halaman Login User

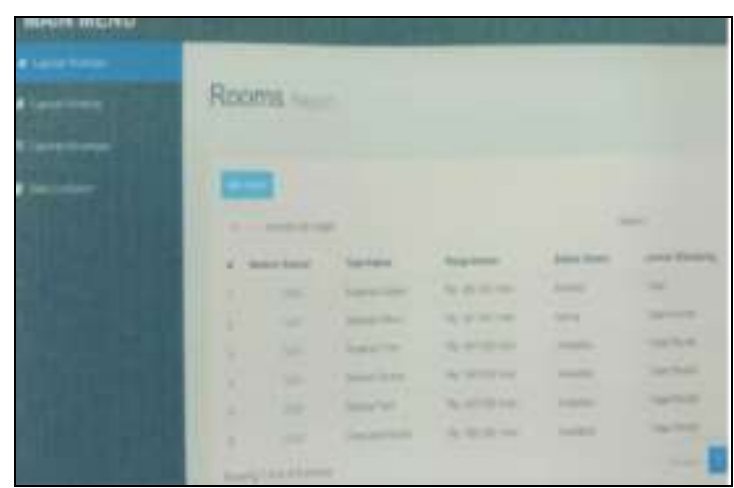

Gambar 17. Laporan Pemesanan Room 


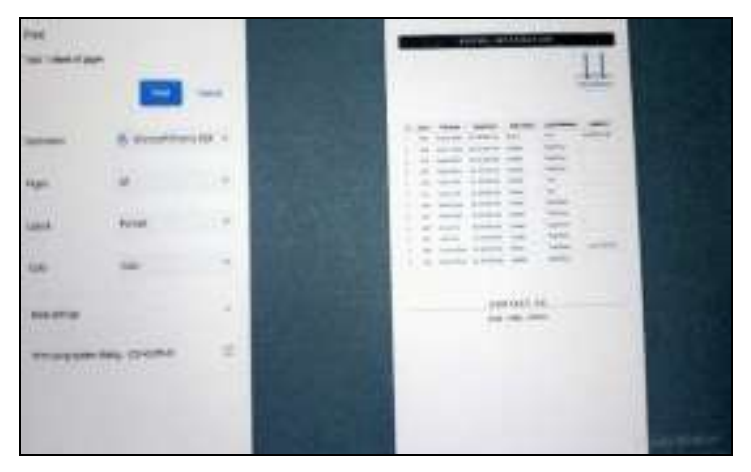

Gambar 18. Laporan untuk pimpinan

\section{SIMPULAN}

Penelitian yang telah dilakukan menghasilkan rancangan sistem dan prototype sistem reservasi dan promosi pada usaha perhotelan yang dapat memberikan kemudahan dalam mencari informasi dan melakukan reservasi pada hotel. Rancangan sistem dan prototype yang telah dibuat akan dapat memberikan banyak kemudahan dalam kegiatan promosi dan transaksi bisnis dibidang perhotelan. Dengan sistem reservasi dan promosi yang dibangun, konsumen dapat mengetahaui fasilitas dan layanan yang diberikan hotel, ketersediaan kamar hotel atau fasilitas yang dibutuhkan serta dapat mengetahui fasilitas promo yang diberikan hotel.

Prototype Website Sistem ini dapat menjadi pedoman untuk membangun sistem reservasi dan promosi pada usaha hotel berbasis website yang dapat memberikan kemudahan dalam penyebaran informasi dan transakasi pada usaha hotel. Saat sistem telah dibangun secara sempurna, agar sistem tersebut dapat berjalan dengan baik tanpa mengandung error oleh pengguna (user) diperlukan tindakan pengujian sistem agar sistem dapat digunakan secara maksimal serta dapat memberi manfaat bagi pengguna dan mendatangkan keuntungan bagi pengusaha.

\section{DAFTAR PUSTAKA}

[1] S. Sugiyarto, dan R. Amaruli, "Pengembangan Pariwisata Berbasis Budaya dan Kearifan Likal," Jurnal Administrasi Bisnis, Vol. 7, No. 1, pp. 45-52. 2018.

[2] Badan Pusat Statistik (BPS). [online]. Available:

https://www.bps.go.id/subject/16/pari wisata.html\#subjekViewTab3

[Accessed: 08-Nov-2019].

[3] Kementerian Pariwitasa Republik Indonesia. [Online]. Available: http://www.kemenpar.go.id/post/stati stik-tingkat-penghunian-kamar-hotelbintang-tahun-2019. [Accssed: 8 Nov- 2018].

[4] Xiangping, B., Canhul, W., \& Fei, F, Application Of Six Sigma to Hotel Service Management and Srvice Science, 2009. MASS '09. International Conference On (pp.14). Wuhan: IEEE, 2009.

[5] Ahmadi dan Hermawan, "E-Business \& E-Commerce”, Yogyakarta: Andi. 2013.

[6] Kadir, A, "Introduction to Internet", Yogyakarta: Andi, 2010

[7] J. Wong., "Internet Marketing for Beginner", Jakarta: Elex Media Komputindo, 2010. 
[8] Bilgihan, A., Okumus, F., Nusair, K., \& Kwun, D.W, “ Information technology applications and competitive advantage in hotel companies", Journal of Hospitality and Tourism Technology, Vol. 2 No. 2, pp. 139-154, 2011.

[9] Bardi, J., Hotel Front Office Management. Fourth Edition. Canada: John Wiley \& Sons, Inc, 2007

[10] R.Mcleod, "Management Information Systems", Jakarta: Salemba Empat, 2008.

[11] Sommerville, I. "SOFTWARE ENGINEERING”, Ninth Edition. United States of America: AddisonWesley. 2010.

[12] Kendall, Kenneth G., \& Kendal Juli E,. "Analisis dan Perancangan Sistem,”, Indeks: Jakarta, 2007.

[13] J.S. Valacich., J.F. George \& J.A Hoffer, "Essential Of Systems Analysis anda Design", 5th Edition ed. B.Horan, Ed. New Jersey: Prentince Hall, 2012.

[14] Tandilian, Friska DL., Purwantar, I Made Adi., \& Jawas, Naser., "Rancang Bangun Sistem Informasi Reservasi Hotel Berbasis Web dengan Framework Codeigniter(Studi Kasus CV,BSB Travel), Jurnal Sistem dan Informatika, Vol. 9, No.2, pp. 7178, 2015.

[15] Purwandari, Nuraini \& Kusumawatie, Arie., "Aplikasi Simpan Pinjam Pada Koperasi Keluarga Karyawan Kalbis Sejahtera Berbasis Wesite", Jurnal ilmiah Komputasi Vol. 18, NO. 3, pp. 287-302, 2019.
[16] Siregar, Victor M.M, "Perancangan Website Sebagai Media Promosi dan Penjualan Produk", Jurnal TAM (Technology Acceptance Model) Vol. 9 No.1, pp. 15-21, 2018.

[17] Dewi, Shanty Kusuma \& Carside, Annisa Kesy., “ Perancangan Website sebagai Medai Promosi dan Penjualan pada Home Industy Abon", Jurnal Teknik Industri Vol. 15, No.2, pp.170-181, 2014

[18] T.W. Oktaviani, "Perancangan User Interface Berbasis Web Untuk Home Automation Gateway yang Berbasis IQRF TR53B", JNTETI, Vol. 3, No. 3, pp. 179-186, 2015.

[19] Setiawan, M. (2017, October). Metode K-Means Untuk Sistem Informasi Pengelompokan Mahasiswa Baru Pada Perguruan Tinggi. In Prosiding Seminar Nasional Darmajaya (Vol. 1, No. 1, pp. 130-145).

[20] Fitria, Y. A. (2019). Visualization Of Data On Earthquake Prone Areasfrom The Analysis of Earthquake Data Vibrations. Test Engineering \& Management, 53015308. 